Article

\title{
Joint Innovation Investment and Pricing Decisions in Retail Supply Chains with Customer Value
}

\author{
Jiali Qu ${ }^{1}$, Benyong $\mathrm{Hu}^{2}$ (D) and Chao Meng ${ }^{3, *}$ \\ 1 School of Management, Xihua University, Chengdu 611731, China; jiali2016@sina.com \\ 2 School of Management and Economics, University of Electronic Science and Technology of China, \\ Chengdu 610039, China; huby@uestc.edu.cn \\ 3 School of Marketing, University of Southern Mississippi, Hattiesburg, MS 39406, USA \\ * Correspondence: meng5656@gmail.com
}

check for updates

Citation: Qu, J.; Hu, B.; Meng, C. Joint Innovation Investment and Pricing Decisions in Retail Supply Chains with Customer Value. Sustainability 2021, 13, 1309. https:// doi.org/10.3390/su13031309

Academic Editor: Marc Lim Received: 30 December 2020 Accepted: 24 January 2021 Published: 27 January 2021

Publisher's Note: MDPI stays neutral with regard to jurisdictional claims in published maps and institutional affiliations.

Copyright: (c) 2021 by the authors. Licensee MDPI, Basel, Switzerland. This article is an open access article distributed under the terms and conditions of the Creative Commons Attribution (CC BY) license (https:// creativecommons.org/licenses/by/ $4.0 /)$.

\begin{abstract}
In the retail industry, customer value has become the key to maintaining competitive advantages. In the era of new retail, customer value is not only affected by the product price, but it is also closely related to innovations, such as value-added services and unique business models. In this paper, we study the joint innovation investment and pricing decisions in a retailer-supplier supply chain based on revenue sharing contracts and customer value. We first find that, in the non-cooperative game, equilibrium only exists in the supplier Stackelberg game. However, revenue sharing contracts cannot coordinate the supply chain in the non-cooperative game. By considering supply chain members' bargaining power, we find that there exists a unique equilibrium for the Nash bargaining product. In addition, revenue sharing contracts can coordinate the supply chain and achieve the optimal consumer surplus. When the supply chain is coordinated, supply chain profit is allocated to the supply chain members based on their bargaining powers.
\end{abstract}

Keywords: innovation investment; pricing; joint decisions; Nash bargaining; customer value

\section{Introduction}

Consumers' purchase behavior is becoming increasingly rational. Rational consumers usually make their purchase decisions based on the value perception of the products. There are many factors that affect customer value, but the product price and value-added services at the retail end are two of the key factors [1-3]. In terms of product pricing, customer value has become one of the important factors that influences a customer's product choices [4]. Therefore, the price factor cannot be considered as the only pricing decision-making reference anymore. This paper is motivated by the emergence of innovative business models in the retail industry. Common retailers (e.g., Target and Walmart) must create a unique customer experience and competitive pricing strategy to compete with their competitors, since they sell similar or substitution goods along with their competitors. For example, the American retailer Target Corporation provides the Circle app for customers to access coupons in order to be different from its competitors, such as Walmart. Fresh Hema, a fresh food retailer in China, offers online order pickup and a free 30 min delivery service within a $3 \mathrm{~km}$ radius. As those retailers adopt unique business models, unique channels, new technology and value-added services, the capital investment decision has become essential. New technologies and value-added services, which bring improved efficiency of product delivery and the quality and freshness of the product, can enhance the consumer's perceived value of the product. In return, the retailers can be confident to set a higher profit margin. For example, Fresh Hema has higher margins compared with traditional grocery stores in China [5]. In fact, the technology connecting consumers and value-added services based on innovation investment has become the support for enterprises to form competitive advantages [1]. It is also a powerful guarantee for enterprises to win at product competition 
and increase their market shares. Therefore, investing in value-added services and making optimal innovation investments have become some of a retailer's key decisions.

Although the new business model and the corresponding value-added services provide some retailers with the chance for higher margins, the retail price decision is still critical, as consumers are sensitive to the product retail price. On the one hand, the product retail price is the basis for retailers to obtain income. The retail price decision will not only have an impact on the retailer itself, but also on the upstream enterprises of the supply chain. In addition, the contract (e.g., revenue sharing contracts) between the retailer and its supplier also affects the retail price and whether the supply chain members can cooperate. In order to cope with market competition and improve customer value, it is necessary to cooperate closely with upstream and downstream enterprises in the supply chain [4]. Rational consumers will decide whether to buy the product based on the comparison with the retained value of the product. Obviously, a high retail price will certainly restrain the market demand. Therefore, focusing on customer value and pricing products scientifically have become key challenges of supply chain operation. Although innovation investment can enhance retailers' competitive advantages and stimulate the potential demand for products, innovation investment will inevitably increase the retailer's cost. Therefore, finding a way to motivate the retailer to make a reasonable innovation investment also constitutes another challenge in supply chain operation.

In this paper, we investigate the revenue sharing contract design for the retailer and its supplier, as well as the retailer's innovation investment decision based on customer value. We define innovation investment as a concept that aggregates any capital investment for developing new business models, new channels, new technology and value-added services. Although revenue sharing contracts have been adopted by multiple industries and investigated by the existing supply chain management literature, how to determine the contract parameters, considering innovation investment and customer value, has not been fully studied. We first construct a demand function that reflects customer value. Based on the demand function, we develop an optimization model that incorporates multiple decisions, including revenue shares, the product wholesale price, product retail price, and innovation investment. We adopt the cooperative Nash bargaining framework to investigate the joint innovation investment and pricing decisions, based on supply chain members' bargaining power. Nash bargaining was first proposed in [6] for the scenario in which two parties choose alternatives from the same feasible alternative set. They can agree on one alternative or end up at a disagreement point. The Nash bargaining approach has been widely used in solving two-party supply chain decision-making problems [7,8]. To the best of our knowledge, our paper is the first in the supply chain literature that investigates the joint innovation investment and pricing decisions in a Nash bargaining supply chain based on customer value. It is also the first that analyzes the impact of supply chain game structure, including the bargaining power, on joint decisions. Our analyses yielded several key findings. When the wholesale price is high or (at the same time) the retailer's revenue share is small, the retailer will utilize uncooperative behavior (i.e., retaliation behavior) in making its decisions, such as a high product retail price. When the retailer and the supplier play a non-cooperative game, equilibrium only exists in the supplier Stackelberg game. However, the supply chain cannot be coordinated by revenue sharing contracts. In the Nash bargaining model, there exists a unique equilibrium for the Nash bargaining product, and revenue sharing contracts can coordinate the supply chain. The Nash bargaining product can split the supply chain profit, continuously based on the bargaining power, and achieve the optimal consumer surplus. In addition, the unique Nash bargaining equilibrium and the bargaining power have a direct matching relationship.

The rest of the study is organized as follows. Section 2 reviews the relevant literature on consumer value and Nash bargaining, as well as joint innovation investment and pricing decisions. Section 3 presents the demand function with consumer value, cost structure, and the assumption. Section 4 analyzes a centralized supply chain model, which is as a benchmark. In Section 5, we provide the decentralized supply chain models for both the 
non-cooperative game and the Nash bargaining game. We also analyze the properties of the optimal solutions. Section 6 discusses the managerial insights. Section 7 concludes the study. Proofs are provided in the Appendix A.

\section{Literature Review}

This paper investigates the joint innovation investment and pricing decisions in a supply chain with customer value and revenue sharing contracts. Thus, the literature review section includes three main research streams: customer value; joint innovation investment and pricing decisions; and revenue sharing contracts.

The research on customer value is mainly focused on two dimensions: one is the creation of customer value, and the other is the influence of customer value on supply chain operation. For the creation of customer value, since customer value has become the source of competitive advantage for enterprises [1], one of the focuses of scholars is how to improve customer value. In terms of the key entry point of customer value creation, it was found in [9] that the promotion and management of customer value perception is the key to successfully creating lasting customer value. It was revealed in Ref [10] that relationship integration and marketing innovation contribute to the creation of customer value and the promotion of competitiveness. At a more specific level, it was shown in Ref [2] that customer-perceived control has an important positive impact on customer value, collaborative creation and service recovery evaluation. Meanwhile, it was proven in Ref [3] that service innovation and customer satisfaction are two key dimensions of customer value creation. However, these studies rarely involve supply chain cooperation. For the second dimension, Luo et al. Ref [4] investigated the impact of customer value and the power structure on product selection and pricing decisions in a retail supply chain. The characteristics and functions of customer value creation in supply and demand management were revealed in Ref [11]. Although these literature focus on the supply chain decisions with customer value, there are few cooperation and incentive mechanisms designed around customer value and bargaining power. Moreover, different from the research above, in this paper, customer value is determined by two factors: price and innovation investment.

Some of the literature focused on innovation investment and pricing decisions. In terms of cooperative innovation, it was proven in Ref [12] that strategic commitment to a price can stimulate downstream innovation in a supply chain. Recently, Nouri et al. Ref [13] investigated the coordination of a manufacturer's innovation and a retailer's promotion, as well as replenishment in a manufacturer-retailer chain with a compensation-based wholesale price contract. The optimal cooperative innovation decision with uncertain technology efficiency was investigated in Ref [14], and the impacts of knowledge spillovers and cartelization on cooperative innovation decisions were analyzed. In terms of joint innovation investment and production decisions, the joint product innovation and production decisions under quality authorization were studied in Ref [15]. This showed that the firm could jump in its optimal production and investment levels over time. In terms of joint investment and pricing decisions, three different decision-making structures were discussed in Ref [16], as well as the impact of product pricing and the timing of an investment decisions on supply chain co-opetition. An optimal control model about dynamic pricing and product and process innovation developed in Ref [17] showed that the pricing rules depended on the sole price optimality condition. Recently, the price match guarantees and investment incentives by a standard Hotelling-type model were investigated in Ref [18]. Yang et al. Ref [19] theoretically analyzed the optimal decisions on product pricing and green technology investment, and they revealed the influence of different initial allowance allocation rules on product pricing and the choice in green technology, as well as total emissions. Different from the research above, in this paper, the price and innovation investment affect customer value, and customer value affects the market demand. 
Revenue sharing contracts were initially used in the video cassette rental industry and gained great success [20]. Now, revenue sharing contracts are widely applied in real supply chain practice [4]. A comprehensive review for revenue sharing contracts was provided in Ref [21], and the most recent review was conducted in [22]. The strengths and limitations of revenue sharing contracts in coordinating a supply chain were introduced in Ref [20]. In terms of performance improvement of the supply chain members, it was proven in Ref [23] that revenue sharing contracts could improve members' profit. The joint impact of exclusive channels and revenue sharing on supply chain members were evaluated in Ref [24]. It was shown in Ref $[25,26]$ that a revenue-sharing contract could improve channel performance in a green supply chain. The effect of decision rights allocation on channel performance under a revenue-sharing contract was investigated in Ref [27]. In terms of supply chain cooperation, the coordination of a supply chain with competing retailers was investigated in Ref [28]. Supply chain coordination with revenue sharing contracts in a two-period newsvendor problem was studied in Ref [29]. The impact of revenue sharing on supply chain coordination under a product substitution scenario was studied in Ref [30,31].

In summary, previous works in the literature summarized in this section have not addressed the joint innovation investment and pricing decisions in the context of customer value or consider cooperative bargaining, which has motivated the study in this paper. This paper is different from the reviewed literature in several ways. First, in this paper, we optimize the joint innovation investment and pricing decisions by considering the effect of customer value on the market demand, which has not been investigated by the literature. Second, we investigate both non-cooperative games and cooperative Nash bargaining games. Third, we obtain the equilibrium condition and the profit allocation scheme based on the supply chain members' bargaining power.

\section{Model Description and Assumptions}

We considered a supply chain consisting of a supplier and a retailer. The supplier produces a single type of product and sells the product to the consumer market through the retailer based on revenue sharing contracts. In order to create differentiation when compared with competitors, the retailer makes decisions on innovation investment for unique business models, distribution channels, and value-added services. In the market, the consumer decides to purchase the product based on their perception of the product value, and the perceived product value is closely related to the product price.

For revenue sharing contracts, let $w$ denote the product's wholesale price per unit and $\phi$ the retailer's share of revenue generated from each unit of the product sold. The supply chain structure is described in Figure 1.

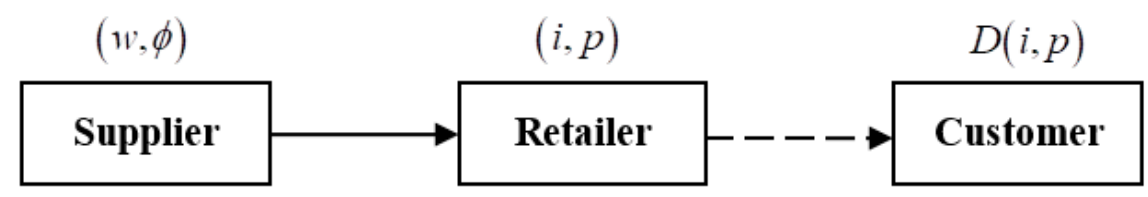

Figure 1. The supply chain structure.

Assuming the retailer's innovation investment can stimulate the market demand, we denote the innovation investment as $i$ and the market size of the product as $a(i)$. For the market size of the product, $a(i)$, we assume that it is a non-subtractive concave function of the innovation investment $i$ :

$$
\frac{d a(i)}{d i}>0 \text { and } \frac{d^{2} a(i)}{d i^{2}}<0
$$

The non-subtractive concave function is a rather weak condition and can capture the most common functions of the innovation investment. The insights of this paper are valid for any non-subtractive concave function of the innovation investment. 
For the consumer, we assume they are heterogeneous in the perception of the product value, and their customer value, $v$, is uniformly distributed over $[0,1]$ within the market size $a(i)$. A similar distribution function of the customer value was commonly used in the literature (e.g., $[4,24,32])$. The insights of this paper are valid for this distribution function. Given the product price $p$, if $v-p \geq 0$ - that is, $v \in[p, 1]$-a consumer will buy the product (see Figure 2). Therefore, the market demand is

$$
D(i, p)=a(i) \int_{p}^{1} d v=(1-p) a(i)
$$

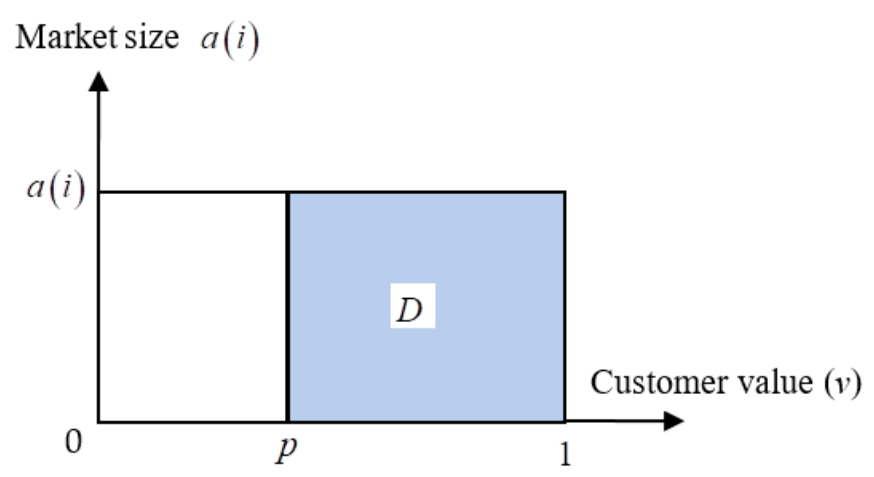

Figure 2. Market demand and distribution of customer value.

Equation (2) contains both the product price and the innovation investment.

Obviously, based on the assumptions above, the consumer net surplus, denoted as CNS $(i, p)$, is modeled as follows:

$$
\operatorname{CNS}(i, p)=a(i) \int_{p}^{1} d v=(1-p) a(i)
$$

From Equation (3), both $\frac{d C N S(i, p)}{d i}=(1-p) \frac{d a(i)}{d i}>0$ (see Equation (1)) and $\frac{d C N S(i, p)}{d p}=$ $-p a(i)<0$ exist, which show that consumers prefer a higher innovation investment and lower product price. In this paper, the customer value is related to the market demand, as shown in Equation (2).

\section{The Benchmark: Centralized Supply Chain Model}

In this section, we provide a centralized supply chain model as the benchmark case. In the centralized supply chain, a central planner determines the innovation investment $i$ and the price $p$ to maximize the expected supply chain profit, denoted by $\pi(i, p)$.

$$
\pi(i, p)=(p-c) D(i, p)-i=(p-c)(1-p) a(i)-i
$$

Based on Equation (4), the centralized decision-making problem is as follows:

$$
\underset{i>0, p>0}{\operatorname{Max}} \pi(i, p)
$$

For the optimal solutions to Equation (5), the following theorem is given.

\section{Theorem 1.}

1. The property of stochastic dominance exists in $\pi(i, p)$ with respect to product retial price $p$;

2. In $i, \pi(i, p)$ is concave;

3. The optimal policies $\left(i_{c}, p_{c}\right)$ for the centralized supply chain are as follows:

$$
p_{c}=\frac{1+c}{2}
$$




$$
\left.\frac{d a(i)}{d i}\right|_{i=i_{c}}=2(1-c)^{-2}
$$

Proof. See Appendix A.

Theorem 1 characterizes the decision properties and the optimal policies. Interestingly, we can see that, in the centralized supply chain, in order to obtain the highest profit, there only exists one combination of the optimal product retail price and the innovation investment. Obviously, an extremely high product retail price will reduce the customer value, compromise product demand, and then have a negative impact on the profit of the supply chain. In addition, although the innovation investment can expand the potential market, $\frac{d^{2} a(i)}{d i^{2}}<0$ shows that too much innovation investment will lead to an uneconomical investment. Therefore, there is an optimal innovation investment for the supply chain.

Based on Equation (4), when $i=i_{c}$ and $p=p_{c}$, the optimal expected profit for the centralized supply chain is as follows:

$$
\pi\left(i_{c}, p_{c}\right)=\frac{1}{2}(1-c)^{2} a\left(i_{c}\right)-i_{c}
$$

For the simplicity of the exposition, we let $\Delta \equiv \frac{1}{2}(1-c)^{2} a\left(i_{c}\right)$. Equation (8) can be rewritten as

$$
\pi\left(i_{c}, p_{c}\right)=\Delta-i_{c}
$$

In addition, when $i=i_{c}$ and $p=p_{c}$, from Equation (3), we can obtain the optimal consumer net surplus as follows:

$$
\operatorname{CNS}\left(i_{c}, p_{c}\right)=\frac{1}{2}(1-c) a\left(i_{c}\right)
$$

Given $\Delta \equiv \frac{1}{2}(1-c)^{2} a\left(i_{c}\right)$, Equation (10) can be rewritten as follows:

$$
\operatorname{CNS}\left(i_{c}, p_{c}\right)=\Delta /(1-c)
$$

The optimization results in the benchmark case will provide a comparative basis for the decision analyses in the decentralized supply chain.

\section{Decentralized Supply Chain Model with Revenue Sharing Contracts}

\subsection{Revenue Sharing Model}

Under the revenue sharing contract $(w, \phi)$, the supplier makes the wholesale price decision and determines the revenue share for the retailer $(w, \phi)$. The retailer needs to determine the innovation investment $i$ and product retail price $p$. The retailer's profit function $\pi_{r}(i, p)$ is as follows:

$$
\pi_{r}(i, p)=(\phi p-w) D(i, p)-i=(\phi p-w)(1-p) a(i)-i
$$

Then, the supplier's profit function $\pi_{s}(w, \phi)$ is as follows:

$$
\pi_{s}(w, \phi)=[(1-\phi) p+w-c] D(i, p)=[(1-\phi) p+w-c](1-p) a(i)
$$

Thus, the retailer should solve the following problem:

$$
\max _{i>0, p>0} \pi_{r}(i, p)
$$

Based on the contract parameters $(w, \phi), \pi_{r}(i, p)$ has the properties in Lemma 1. 


\section{Lemma 1.}

1. The property of stochastic dominance exists in $\pi_{r}(i, p)$ with respect to $p$;

2. In $i, \pi_{r}(i, p)$ is concave;

3. The best response functions for the retailer on $p$ and $i$ are as follows:

$$
\begin{gathered}
p=\frac{1+w / \phi}{2} \\
\frac{d a(i)}{d i}=2(1-w / \phi)^{-2}
\end{gathered}
$$

Proof. See Appendix A. $\square$

Lemma 1 shows that the retailer's decisions are closely related to the wholesale price and the revenue share. When the wholesale price is high or (at the same time) the revenue sharing ratio is small, the retailer can only obtain a small profit margin. Then, the retailer will take the following uncooperative behaviors. One is that the retailer will increase the product retail price for a higher profit margin. However, a high product retail price will reduce customer value and then restrain market demand, which in turn has a direct negative impact on supplier's revenue. The other is that the high wholesale price and small revenue share make the retailer more sensitive to innovation investment; that is, $\frac{d a(i)}{d i}$ becomes larger. When $\frac{d a(i)}{d i}$ is large, in order to reduce the operation cost, the retailer will choose to reduce the innovation investment. The lack of innovation investment will also restrain the market demand and have a direct negative impact on the supplier's revenue. For the supplier, a high wholesale price is not always in its own interest. The potential uncooperative behaviors will be the consequence of a high wholesale price or a small revenue share for the retailer. Therefore, due to the interdependency of the decisions, the supplier must consider the retailer's retaliatory behavior when setting the wholesale price and revenue share.

It is worth noting that, according to Lemma 1, the best response functions for the retailer's innovation investment and pricing decisions only depend on the ratio $w / \phi$. This means that the retailer's profit $\pi_{r}(i, p)$ can be expressed as follows:

$$
\pi_{r}(i, p)=\phi(p-w / \phi)(1-p) a(i)-i
$$

Clearly, only the ratio $w / \phi$ of the revenue sharing contract $(w, \phi)$ has a direct impact on the supply chain profit, Given $w / \phi, \phi$ can realize the division of the supply chain profit between the retailer and the supplier. Therefore, this paper assumes $w / \phi=c$ in the revenue sharing contract $(w, \phi)$. Then, the retailer and the supplier will make decisions on $\phi$ and $w / \phi=c$.

Based on the assumptions above, this paper will examine non-cooperative games (Section 5.2) and a Nash bargaining game (Section 5.3) on the joint innovation investment and pricing decisions, respectively.

\subsection{Non-Cooperative Games}

In the non-cooperative game, we assumed a vertical competition game between the supplier and retailer as either a Stackelberg game or a Nash game. Those games are named as the supplier Stackelberg (SS) game, retailer Stackelberg (RS) game, and vertical Nash (VN) game, respectively.

The following theorem shows the equilibrium condition for the non-cooperative game in the decentralized supply chain.

\section{Theorem 2.}

1. Equilibrium only exists in the SS game; 
2. The unique equilibrium of the SS game is $\phi_{S S}=i_{c} / \Delta, w_{S S}=c i_{c} / \Delta, p_{S S}=p_{c}$ and $i_{S S}=i_{c}$;

3. The supply chain cannot be coordinated with revenue sharing contracts in a non-cooperative game.

Proof. See Appendix A.

Theorem 2 reveals the equilibrium condition of the supply chain decisions in the non-cooperative game. We can find two obvious shortcomings in the non-cooperative game. First, a non-cooperative game cannot coordinate the supply chain with revenue sharing contracts. Second, in the non-cooperative game, it is impossible to describe the bargaining power in the supply chain continuously. Although all the game types may exist in real practice, the supply chain cannot be coordinated. In the next section, we will investigate the joint innovation investment and pricing decisions in a Nash bargaining supply chain.

\subsection{Nash Bargaining Game}

5.3.1. Model and Equilibrium of the Nash Bargaining Product

Lemma 1 shows that the retailer will make the pricing and innovation investment decisions based on $w / \phi=c$. In addition, given $w / \phi=c, \phi$ is the key basis of profit division in the supply chain. Therefore, in this section, we assume $w / \phi=c$ is a constant, and the supplier and the retailer bargain over $\phi$. We denote the supplier's bargaining power by $\alpha \in[0,1]$, which is exogenously given. Thus, $1-\alpha$ is the retailer's bargaining power. We also denote the supplier's and the retailer's threat points by $f_{s}$ and $f_{r}$, respectively. Then, we express the Nash product for the supplier and the retailer bargaining on $\phi$ under $w / \phi=c$ as

$$
\Phi=\left(\pi_{s}-f_{s}\right)^{\alpha}\left(\pi_{r}-f_{r}\right)^{1-\alpha}
$$

In addition, the Nash bargaining product is expressed as

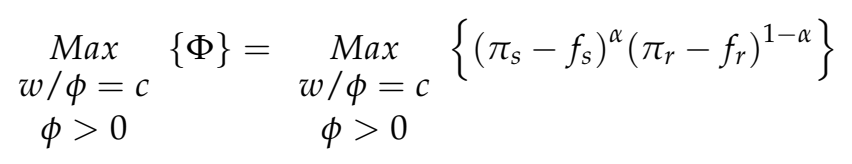

where, based on Theorem 1 and Lemma 1, $w / \phi=c$, and based on Equations (15) and (16), $\pi_{r}$ and $\pi_{s}$ are expressed as follows, respectively:

$$
\begin{aligned}
& \pi_{r}=\phi\left(p_{c}-c\right)\left(1-p_{c}\right) a\left(i_{c}\right)-i_{c} \\
& \pi_{s}=(1-\phi)\left(p_{c}-c\right)\left(1-p_{c}\right) a\left(i_{c}\right)
\end{aligned}
$$

In Equations (20) and (21), $p_{c}=\frac{1+c}{2}$. By letting $\Delta \equiv \frac{1}{2}(1-c)^{2} a\left(i_{c}\right)$, we obtain

$$
\begin{gathered}
\pi_{r}=\phi \Delta-i_{c} \\
\pi_{s}=(1-\phi) \Delta
\end{gathered}
$$

For the simplicity of the exposition, we assume $f_{s}=f_{r}=0$, which means the firms never reach an agreement if one's profit is zero. Then, the Nash bargaining product from Equation (19) can be rewritten as

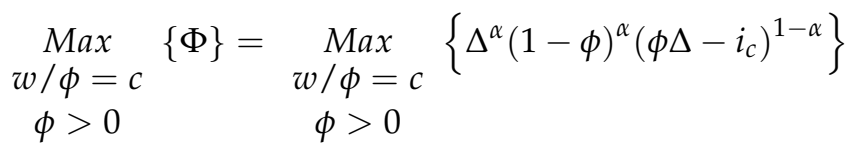

The Nash bargaining product has the following properties, as shown in Theorems 3 and 4 . 
Theorem 3. The Nash bargaining product expressed in Equation (24) is equivalent to an RS game at $\alpha=0$ and equivalent to an SS game at $\alpha=1$.

Proof. The proof is straightforward.

Theorem 3 reveals that the Nash bargaining product in Equation (24) degenerates into equilibriums of the Stackelberg games under the condition of extreme monopoly power.

Theorem 4 . When $\alpha \in(0,1)$, the following are true:

1. The unique equilibrium for the Nash bargaining product is as follows:

$$
\phi_{d}=1-\alpha\left(1-i_{c} / \Delta\right)
$$

2. The supplier's and the retailer's optimal expected profits are $\pi_{r}=(1-\alpha)\left(\Delta-i_{c}\right)$ and $\pi_{s}=\alpha\left(\Delta-i_{c}\right)$, respectively;

3. The Nash bargaining product can coordinate the supply chain with revenue sharing contracts.

Proof. See Appendix A.

From Theorem 4, we can see that the Nash bargaining model has the following three advantages. First, the model has a unique optimal solution, which shows that the contract designed in this paper presents enforceability. Second, the designed contract can achieve supply chain coordination and help enhance the competitiveness of the entire supply chain. Third, the designed contract includes the supply chain members' bargaining power, which improves the stability of the equilibrium achieved by the cooperation.

The above analysis shows that, in the Nash bargaining supply chain with revenue sharing contracts, the optimal contract parameters, denoted as $w_{d}$ and $\phi_{d}$, are $\phi_{d}=1-$ $\alpha\left(1-i_{c} / \Delta\right)$ and $w_{d}=\phi_{d} c$. In addition, the optimal innovation investment, denoted as $i_{d}$, and the optimal price, denoted as $p_{d}$, are $i_{d}=i_{c}$ and $p_{d}=p_{c}=\frac{1+c}{2}$. Here, $i_{c}$ is decided by $\left.\frac{d a(i)}{d i}\right|_{i=i_{c}}=2(1-c)^{-2}$.

\subsubsection{Impact of Bargaining Power}

In this section, we will discuss the impact of the bargaining power on the profit of the supply chain members, the game equilibrium strategies and consumer surplus.

Corollary 1. Based on the bargaining power, the unique Nash bargaining equilibrium can realize continuous division of the supply chain profit.

Figure 3 illustrates Corollary 1. Two interesting aspects can be found. One is that, in the Nash bargaining product, the equilibrium includes the continuous characterization of supply chain members' bargaining power. Obviously, this is different from the three discrete game structures in non-cooperative games: retailer-or supplier-dominated and the Nash game. The other is that this proposed Nash bargaining product can realize profit distribution based on supply chain members' bargaining power. The member with the stronger bargaining power will obtain a higher profit. When the bargaining powers are close, two supply chain members will share the additional profits from supply chain cooperation. This provides guidance for profit allocation. Moreover, supply chain coordination is possible under certain conditions. 


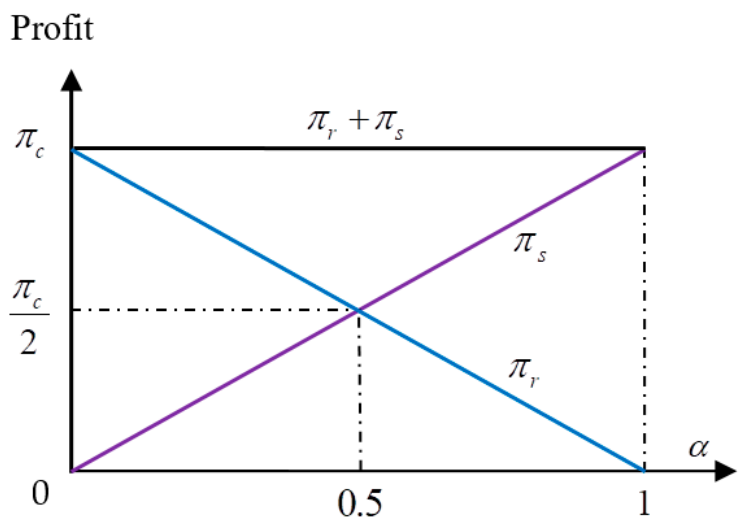

Figure 3. Impact of bargaining power on profits.

Corollary 2. The unique Nash bargaining equilibrium and the bargaining power have a direct matching relationship.

Figure 4 provides an illustration for Corollary 2. This corollary provides guidance for the contract design and supply chain coordination. It can be seen that the contract parameters have direct dynamic correlations with the supply chain members' bargaining power. Obviously, this supply chain coordination mechanism reflects the bargaining power of the supply chain members in various situations, which also makes supply chain cooperation stable.

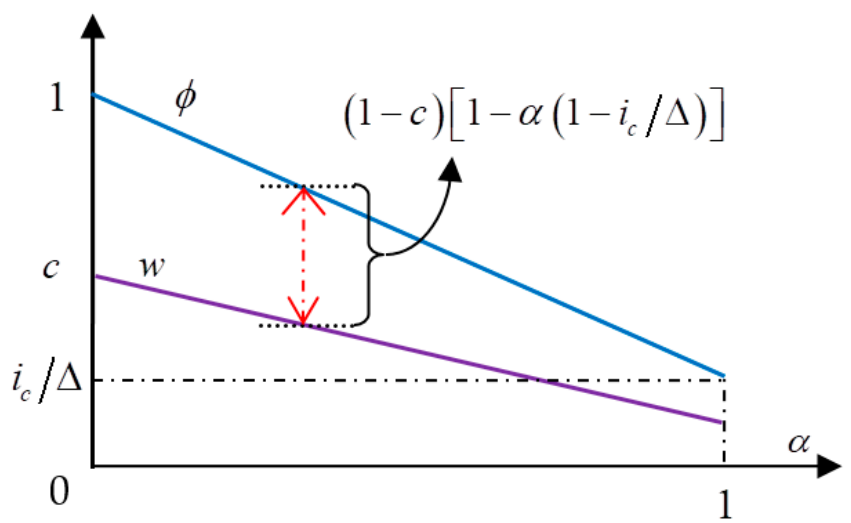

Figure 4. Impact of bargaining power on the equilibrium.

Corollary 3. The proposed Nash bargaining product can integrate the bargaining power, the optimal profit of the supply chain and the maximum consumer net surplus simultaneously.

Figure 5 provides an illustration for Corollary 3. Interestingly, from Corollary 3, we find that the equilibrium in the proposed Nash bargaining product can achieve the consumer net surplus and the supply chain profit in the decentralized case as it does in the centralized case. An interesting observation from Figure 5 is that the equilibrium outcomes, including the optimal consumer net surplus and the optimal supply chain profit, are not affected by the bargaining power. This also shows the advantage of the proposed Nash bargaining product from another perspective. 


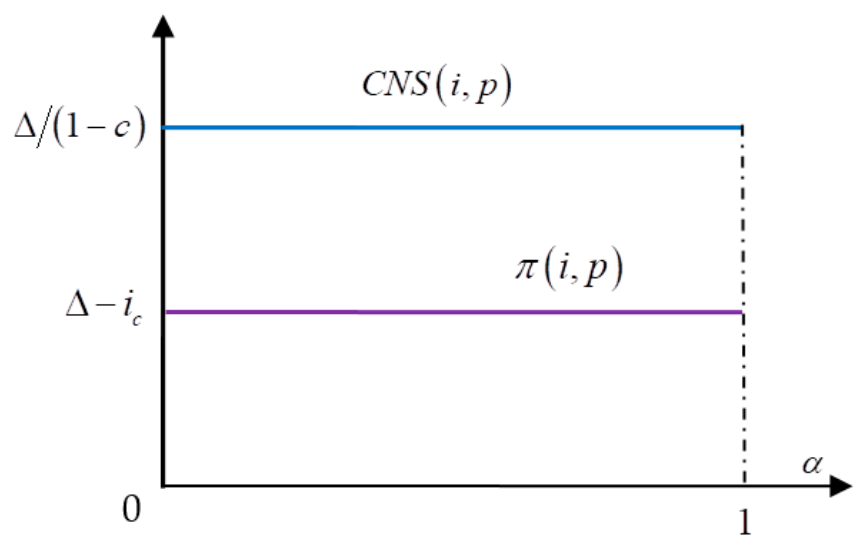

Figure 5. Impacts of bargaining power on the supply chain profit and consumer net surplus.

\subsection{Nash Bargaining vs. Non-Cooperative Game}

This section will compare the supply chain profits and consumer net surplus under different game types. Two significant findings can be observed in Table 1. First, for the decentralized supply chain, the non-cooperative game cannot achieve a feasible cooperation scheme, and supply chain cooperation is invalid (where the supplier monopolizes the profit of supply chain cooperation). Second, in the Nash bargaining game, the proposed Nash bargaining product can achieve a feasible cooperation scheme, and the equilibrium can achieve the coordination of the decentralized supply chain. In this case, not only do the supplier and the retailer share the profit from the supply chain cooperation, but the consumer net surplus is optimal.

Table 1. Profit and surplus.

\begin{tabular}{cccccc}
\hline & \multicolumn{3}{c}{ Expected Profit } & \multirow{2}{*}{ Consumer Net Surplus } \\
\cline { 2 - 5 } & & Retailer & Supplier & Supply Chain & \\
\hline \multirow{2}{*}{ Non-cooperative game } & VN & 0 & 0 & 0 & 0 \\
& RS & 0 & 0 & 0 & 0 \\
& SS & 0 & $\Delta-i_{c}$ & $\Delta-i_{c}$ & $\Delta /(1-c)$ \\
\hline Nash bargaining & & $(1-\alpha)\left(\Delta-i_{c}\right)$ & $\alpha\left(\Delta-i_{c}\right)$ & $\Delta-i_{c}$ & $\Delta /(1-c)$ \\
\hline Centralized model & - & - & $\Delta-i_{c}$ & $\Delta /(1-c)$ \\
\hline
\end{tabular}

\section{Discussions}

In this section, we discuss the managerial insights obtained from the analytical and numerical results. For the centralized supply chain, there only exists one combination of the optimal product retail price and the innovation investment. An extremely high product retail price will reduce the customer value, compromise product demand and have a negative impact on the profit of the supply chain. This means that the supply chain should never seek a high retail price. As Lemma 1 indicates, it is optimal for the supplier to seize an extremely large portion of the supply chain profit by using its supply chain position. The retailer would not cooperate with the supplier by setting a high retail price, which reduces the market demand and revenue for the supplier. In addition, Theorem 2 demonstrates that the supply chain cannot be coordinated in a supplier Stackelberg game. Therefore, the supplier needs to make its decisions wisely to make sure its own profit is maximized. Different from the Stackelberg game, the Nash bargaining model can help achieve supply chain coordination in revenue sharing contracts. This means that in real practice, there exists the possibility that both the supplier and the retailer can improve their profits. In addition, the supply chain decisions can be made based on supply chain players' bargaining powers. This improves the stability of the equilibrium achieved by cooperation. In addition, the consumer net surplus is also optimal in the Nash 
bargaining game. Therefore, those results can be used in real practice to assist supply chain decision-making.

\section{Conclusions}

In this paper, from the perspective of customer value, we used the cooperative bargaining framework to investigate joint innovation investment and pricing decisions in a supply chain with revenue sharing contracts. We first developed a centralized supply chain model and showed that the model had a unique equilibrium solution. Second, we investigated the non-cooperative game and found that when the wholesale price was high or (at the same time) the revenue share was small for the retailer, the retailer would take retaliatory behavior, such as setting a high product retail price. In addition, equilibrium only existed in the supplier Stackelberg game. However, the supply chain could not be coordinated by revenue sharing contracts. Third, in the Nash bargaining model, we found that there existed a unique equilibrium for the Nash bargaining product, and revenue sharing contracts could coordinate the supply chain. The Nash bargaining product could split the supply chain profit based on the bargaining power continuously. In addition, the unique Nash bargaining equilibrium and the bargaining power had a direct matching relationship. In the equilibrium, the net surplus of consumers was not affected by the supply chain members' bargaining power. This paper is the first in the supply chain literature that investigates the joint innovation investment and pricing decisions in a Nash bargaining supply chain based on customer value. The existing literature, such as that by Kim and Ahmed [18] and Yang et al. [19], did not focus on the impact of the supply chain game structure on the coordination outcomes. In addition, this paper is also the first to analyze the impact of the supply chain game structure, including the bargaining power, on the joint decisions.

Further research may consider additional real-world factors, such as market competition. This is because competitors' pricing strategies and business models also affect the market demand and the retailer's decisions. In addition, other contracts can be considered, and comparative analyses can be conducted to show which contract type is favorable to each supply chain member. In addition, the proposed models and theorems are planned to be tested via real retail supply chains, and parameter values will be obtained after consultancy with practicing managers.

Author Contributions: Conceptualization, J.Q.; methodology C.M.; writing-original draft J.Q. and B.H.; supervision C.M. All authors have read and agreed to the published version of the manuscript.

Funding: The authors are grateful to the editor and the anonymous reviewers for their insightful and constructive comments. This research is supported by the National Social Science Foundation of China (No. 18BGL108).

Institutional Review Board Statement: Not applicable.

Informed Consent Statement: Not applicable.

Data Availability Statement: Not applicable.

Conflicts of Interest: The authors declare no conflict of interest.

\section{Appendix A}

\section{Proof of Theorem 1.}

1. From Equation (4), we get $\frac{d \pi(i, p)}{d p}=(1+c-2 p) a(i)$ and $\frac{d^{2} \pi(i, p)}{d p^{2}}=-2 a(i)$. This is the property of stochastic dominance, which exists in $\pi(i, p)$ with respect to $p$. Therefore, by letting $\frac{d \pi(i, p)}{d p}=0$, we get $p_{c}=\frac{1+c}{2}$;

2. When $p_{c}=\frac{1+c}{2}$, from Equation (4), we get $\frac{d \pi(i, p)}{d i}=(p-c)(1-p) \frac{d a(i)}{d i}-1$ and $\frac{d^{2} \pi(i, p)}{d i^{2}}=(p-c)(1-p) \frac{d^{2} a(i)}{d i^{2}}$. By combining this with $\frac{d^{2} a(i)}{d i^{2}}$, we get $\frac{d^{2} \pi(i, p)}{d i^{2}}<0$. 
Therefore, $\pi(i, p)$ is concave in $i$. By letting $\frac{d \pi(i, p)}{d i}=0$, we get $\left.\frac{d a(i)}{d i}\right|_{i=i_{c}}=2(1-c)^{-2}$.

\section{Proof of Theorem 2.}

1. Since the property of stochastic dominance exists in $\pi_{s}(w, \phi)$ with respect to $w$ and $\phi$, the supplier will let $w=1$ and $\phi=0$. These mean there are no equilibrium solutions in the $\mathrm{VN}$ game or the RS game;

2. In the SS game, Lemma 1 shows that Equations (15) and (16) are the retailer's best response functions. The supplier will get the maximum profit of the whole supply chain by $\phi=i_{c} / \Delta, w=c i_{c} / \Delta$. Therefore, the equilibrium of the SS game is $\phi_{S S}=$ $i_{c} / \Delta, w_{S S}=c i_{c} / \Delta, p_{S S}=p_{c}$ and $i_{S S}=i_{c}$;

3. Statement 1 of Theorem 2 shows that there are no RS games or a VN games in the non-cooperative game between the supplier and retailer. In addition, in the SS game, the retailer can only get zero profit. That means the cooperation is invalid in the supply chain under a non-cooperative game. Therefore, the supply chain cannot be coordinated with the revenue sharing contracts in a non-cooperative game.

\section{Proof of Theorem 4.}

1. From $\Phi=\Delta^{\alpha}(1-\phi)^{\alpha}\left(\phi \Delta-i_{c}\right)^{1-\alpha}$, we get $\frac{d \Phi}{d \phi}=\Delta\left(\frac{1-\phi}{\phi-i_{c} / \Delta}\right)^{\alpha}\left(1-\alpha \frac{1-i_{c} / \Delta}{1-\phi}\right)$ and $\frac{d^{2} \Phi}{d \phi^{2}}=-\Delta \alpha \frac{1-\alpha}{\phi-i_{c} / \Delta}\left(\frac{1-i_{c} / \Delta}{1-\phi}\right)^{2}\left(\frac{1-\phi}{\phi-i_{c} / \Delta}\right)^{\alpha}<0$. By combining $\alpha \in(0,1), \phi \in(0,1)$ and $\phi>i_{c} / \Delta$, we get $\frac{d^{2} \Phi}{d \phi^{2}}<0$. Therefore, $\Phi$ is concave in $\phi$. By letting $\frac{d \Phi}{d \phi}=0$, we get $\phi_{d}=1-\alpha\left(1-i_{c} / \Delta\right)$

2. When $\phi=\phi_{d}$, from Equations (22) and (23), we get $\pi_{r}=(1-\alpha)\left(\Delta-i_{c}\right)$ and $\pi_{s}=$ $\alpha\left(\Delta-i_{c}\right)$, respectively;

3. In this proposed Nash bargaining product, $w / \phi=c$ is present. When $w / \phi=c$, from Theorem 1 and Lemma 1, we know the decentralized supply chain will choose the same pricing and innovation investment as the centralized supply chain. In addition, the second statement of Theorem 4 shows that $\pi_{r}>0$ and $\pi_{s}>0$. As such, the proposed Nash bargaining product can coordinate the supply chain with the revenue sharing contracts.

Proof of Lemma 1. This proof is similar to the proof of Theorem 1.

\section{References}

1. Woodruff, R.B. Customer value: The next source for competitive advantage. J. Acad. Mark. Sci. 1997, 25, 139-153. [CrossRef]

2. Guo, L.; Lotz, S.L.; Tang, C.; Gruen, T.W. The Role of Perceived Control in Customer Value Cocreation and Service Recovery Evaluation. J. Serv. Res. 2016, 19, 39-56. [CrossRef]

3. Mahmoud, M.A.; Hinson, R.; Anim, P.A. Service innovation and customer satisfaction: The role of customer value creation. Eur. J. Innov. Manag. 2018, 21, 402-422. [CrossRef]

4. Luo, Z.; Chen, X.; Kai, M. The effect of customer value and power structure on retail supply chain product choice and pricing decisions. Omega 2018, 77, 115-126. [CrossRef]

5. Forbes. A Visit to Hema in Beijing Changed My View of Grocery Shopping. Available online: https://www.forbes.com/sites/ hendriklaubscher/2018/10/10/a-visit-to-hema-in-beijing-changed-my-view-of-grocery-shopping/?sh=44ea84ae3c54 (accessed on 6 November 2020).

6. Nash, J. The bargaining problem. Econometrica 1950, 18, 155-162. [CrossRef]

7. Gjerdrum, J.; Shah, N.; Papageorgiou, L.G. Fair transfer price and inventory holding policies in two-enterprise supply chains. Eur. J. Oper. Res. 2002, 143, 582-599. [CrossRef]

8. Wu, D.D. Bargaining in supply chain with price and promotional effort dependent demand. Math. Comput. Model. 2013, 58, 1659-1669.

9. Kumar, V.; Reinartz, W. Creating Enduring Customer Value. J. Mark. 2016, 80, 36-68. [CrossRef]

10. Sanchezgutierrez, J.; Cabanelas, P.; Lampon, J.F.; Gonzalezalvarado, T.E. The impact on competitiveness of customer value creation through relationship capabilities and marketing innovation. J. Bus. Ind. Mark. 2019, 34, 618-627. [CrossRef] 
11. Jaaskelainen, A.; Heikkila, J. Purchasing and supply management practices in customer value creation. Supply Chain Manag. 2019, 24, 317-333. [CrossRef]

12. Gilbert, S.M.; Cvsa, V. Strategic commitment to price to stimulate downstream innovation in a supply chain. Eur. J. Oper. Res. 2003, 150, 617-639. [CrossRef]

13. Nouri, Mmanufacturer's innovation and retailer's promotion and replenishment using a compensation-based wholesale price con; Hosseini-Motlagh, S.M.; Nematollahi, M.; Sarker, B.R. Coordinating tract. Int. J. Prod. Econ. 2018, 198, 11-24.

14. Zhou, X.; Yang, S.; Wang, G. Impacts of knowledge spillovers and cartelization on cooperative innovation decisions with uncertain technology efficiency. Comput. Ind. Eng. 2020, 143, 106395. [CrossRef]

15. Li, Z.; Ni, J. Dynamic product innovation and production decisions under quality authorization. Comput. Ind. Eng. 2018, 116, 13-21. [CrossRef]

16. Gurnani, H.; Erkoc, M.; Luo, Y. Impact of product pricing and timing of investment decisions on supply chain co-opetition. Eur. J. Oper. Res. 2007, 180, 228-248. [CrossRef]

17. Chenavaz, R. Dynamic pricing, product and process innovation. Eur. J. Oper. Res. 2012, 222, 553-557. [CrossRef]

18. Kim, B.C.; Ahmed, M. Price-Match Guarantees and Investment Incentives. Inf. Econ. Policy. 2020, 53, 100891. [CrossRef]

19. Yang, W.; Pan, Y.; Ma, J.; Yang, T.; Ke, X. Effects of allowance allocation ules on green technology investment and product pricing under the cap-and-trade mechanism. Energy Policy 2020, 139, 111333. [CrossRef]

20. Cachon, G.P.; Lariviere, M.A. Supply chain coordination with revenue-sharing contracts: Strengths and limitations. Manag. Sci. 2005, 51, 30-44. [CrossRef]

21. Cachon, G.P. Supply chain coordination with contracts. In Handbooks in Operations Research and Management Science; Elsevier: Amsterdam, The Netherlands, 2003; Volume 11, pp. 227-339.

22. Bart, N.; Chernonog, T.; Avinadav, T. Revenue-sharing contracts in supply chains: A comprehensive literature review. Int. J. Prod. Res. 2020, 1-26. [CrossRef]

23. Pan, K.; Lai, K.K.; Leung, S.C.; Xiao, D. Revenue-sharing versus wholesale price mechanisms under different channel power structures. Eur. J. Oper. Res. 2010, 203, 532-538. [CrossRef]

24. Chen, J.; Bell, P.C. Implementing market segmentation using full-refund and no-refund customer returns policies in a dual-channel supply chain structure. Int. J. Prod. Econ. 2012, 136, 56-66. [CrossRef]

25. Song, H.; Gao, X. Green supply chain game model and analysis under revenue-sharing contract. J. Clean. Prod. 2018, 170, 183-192. [CrossRef]

26. Panja, S.; Mondal, S.K. Exploring a two-layer green supply chain game theoretic model with credit linked demand and mark-up under revenue sharing contract. J. Clean. Prod. 2020, 250, 119491. [CrossRef]

27. Avinadav, T. The effect of decision rights allocation on a supply chain of perishable products under a revenue-sharing contract. Int. J. Prod. Econ. 2020, 225, 107587. [CrossRef]

28. Yao, Z.; Leung, S.C.; Lai, K.K. Manufacturer's revenue- sharing contract and retail competition. Eur. J. Oper. Res. 2008, 186, 637-651. [CrossRef]

29. Linh, C.T.; Hong, Y. Channel coordination through a revenue sharing contract in a two-period newsboy problem. Eur. J. Oper. Res. 2009, 198, 822-829. [CrossRef]

30. Wang, Y. Joint pricing-production decisions in supply chains of complementary products with uncertain demand. Oper. Res. 2006, 54, 1110-1127. [CrossRef]

31. Avinadav, T.; Chernonog, T.; Perlman, Y. Consignment contract for mobile apps between a single retailer and competitive developers with different risk attitudes. Eur. J. Oper. Res. 2015, 246, 949-957. [CrossRef]

32. Chiang, W.Y.K.; Chhajed, D.; Hess, J.D. Direct marketing, indirect profits: A strategic analysis of dual-channel supply-chain design. Manag. Sci. 2003, 49, 1-20. [CrossRef] 